\title{
Yusuf Er
}

Gazi Teknik ve Endüstri Meslek Lisesi Metalürji Eğitimi Bölümü yusufer23@hotmail.com 23040 Elazığ, Türkiye

http://dx.doi.org/10.12739/NWSA.2013.8.2.1A0343

\section{NİKEL - KROM - MOLİBEN ALAŞIMININ HASSAS DÖKÜM KALIPLAMA YÖNTEMİYLE DÖKÜLEBILIRLIĞİNIN ARAŞTIRILMASI}

\section{ÖZET}

Bu çalışmada, Ni-Cr-Mo alaşımı bir malzeme, hassas döküm yöntemiyle poliüretan köpük model kullanllarak düzenli, açık gözenekli formda üretilmiştir. Çalışmada; 10,20 ve 30 ( \pm 3$)$ ppi gözenek boyutlarında ve sırasıyla 0,0008, 0,0017, 0,0027 gr/mm yoğunluklarında poliüretan köpükler, model olarak kullanılmıştır. Hazırlanan modeller hassas döküm yöntemiyle kalıplanarak, savurmalı döküm cihazında yeterli sayıda numune üretimi gerçekleştirilmiştir. Üretilen numunelerin açık gözenekli olarak döküle bilirliği, gözenek boyutlarının kontrol edilebilir özelliği ve numunelerin yoğunluk oranları araştırılmıştır. Sonuç olarak; Ni-Cr-Mo alaşımının gözenek boyutlarının kontrol edilerek, açık gözenekli olarak döküle bilirliği ve yoğunluk özellikleri gözlenmiştir.

Anahtar Kelimeler: Açık Gözenek, Ni Esaslı Alaşımlar, Yoğunluk, Hassas Döküm Yöntemi, Poliüretan Köpük

\section{INVESTIGATION OF CASTABLE NICKEL - CHROMIUM - MOLYBDENUM ALLOY WITH OPEN STRUCTURE FORM BY PRECISION CASTING METHOD}

\section{ABSTRACT}

In this study, Ni-Cr-Mo alloy, is manufactured using precision casting method from a polyurethane foam model in a regular and openpore form. The samples produced have 10, 20 and 30 ( \pm 3 ) ppi of pore sizes and $0.0008,0.0017,0.0027 \mathrm{gr} / \mathrm{mm}^{3}$ densities respectively by using polyurethane foams models. A sufficient number of samples were produced by precision casting methods with casting blower device. Samples, the open porous castable, the pore size can be controlled by the property and the intensity ratios of the samples were investigated. As a result, the Ni-Cr-Mo alloy castable by controlling the pore size, open porosity and density characteristics has been observed.

Keywords: Open Pore, Ni-Based Alloys, Density, Precision Casting Method, Polyurethane Foam 


\section{GİRISS (INTRODUCTION)}

Metalik köpüklerin birçok üretim yöntemleri vardır. Bu yöntemlerle üretilen gözenekli metaller değişik amaçlara yönelik olarak birçok kullanım alanı bulurlar [1]. Bu yöntemlerden iki aşamalı hassas döküm yönteminde, polimerik köpük gözenekleri kopya edilerek açık hücreli metal köpükleri üretilir. Bu yöntemde basit bir polimerik köpük kullanılmasıyla köpüğün gözenekleri iyi bir şekilde kontrol edilebilir. Bu gözenekli malzemelerin özellikleri, temel metal alaşım ve bağıl yoğunluk özellikleri ile ilişkilidir [2]. Curran, (2001); Metal tozlarıyla, toz metalürjisi yöntemi ile elde edilen köpüklerin mukavemetinin metal veya fiber tanecikleri arasında ki en küçük temas noktalarıyla ilgili olduğunu ifade etmiştir [3]. Bu tür toz metalürjisi yöntemi ile elde edilen köpüklerin kendine özgü mukavemetlerinin düşük olduğunu belirtmiştir. Yamada ve arkadaşları (2000) ise; Poliüretan köpük ön modelli, infilitrasyon yöntemi ile açık gözenekli yapıda hassas döküm gerçekleştirmiş ve üretilen malzemelerin yüksek kaliteli ve güvenilir olduğunu, gözeneklik oranının o98'e kadar çıkabileceğini ifade etmiştir [4]. Yamada bu yöntemle herhangi bir alaşım veya metalin dökülebileceğini de belirtmiştir. Diğer taraftan Wen (2001) gözenekli malzemelerin mukavemet ve elastikiyet katsayısı bakımından, doğal kemiğin mukavemet ve elastikiyet katsayısına mümkün olduğu kadar yakın olarak ayarlanıp üretilebildikleri için, özellikle çok cazip olduğunu belirtmiştir [5]. Bu yüzden doğal kemiğin biyomekanik özelliklerini sağlamak için yüksek mukavemetli ve Young modülü uyumlu, kemik yerine geçen yeni materyaller geliştirmek vazgeçilmezdir. Araştırmalar göstermiştir ki, gözenekli kemik yerine implante edilecek gözenekli malzemenin ortalama gözenek boyutunun kemik ilerlemesine imkân verecek ölçülerde olması gerekmektedir. Bu değer, yaklaşık olarak 200-500 um civarında olmalıdır [6]. Bu çalışmada, üç farklı gözenek boyutlarında poliüretan köpük modeller kullanılarak, hassas döküm yöntemiyle açık gözenekli numuneler üretilmiş ve üretilen numunelerin yoğunluk özellikleri araştırılmıştır.

\section{2. ÇALIŞMANIN ÖNEMI (RESEARCH SIGNIFICANCE)}

Bu çalışmada üretilmiş olan numune canlılarda kemik hasarlarında biyomalzeme olarak kullanılmak amacıyla üretilmiştir. Numunenin hassas döküm yoluyla üretilmiş olması ve gözenekli bir yapıda olması davranış özellikleri itibariyle kemiğin davranışlarına çok yakın olması açısından önemlidir. Kemiğin gözenekli yapısı, bir taraftan kemik içerisindeki sıvıların dolaşımına müsaade ederken diğer taraftan kemiğin özgül ağırlığına bir hafiflik vermekte ve dayanımını arttırmaktadır. Üretilmiş olan bu numuneler kemiğin özelliklerine benzerlik teşkil etmesi açısından önemlidir.

\section{DENEYSEL YÖNTEM (EXPERIMENTAL METHOD)}

Bu çalışmada numune malzemesi olarak nikel esaslı alaşım kullanıldı. Alman Böhler firması tarafından ticari olarak üretilen alaşımın temelini 61,5'lik bir oranla nikel teşkil etmektedir. 26,0 krom ve olı,0 molibden alaşımın diğer temel elemanlarıdır. Alaşımda az miktarda silisyum ve karbon da bulunmaktadır. Tablo 1'de firmanın alaşımın içeriğine ilişkin verdiği yüzde oranları görülmektedir. Tablo 2'de deneyde kullanılan alaşıma ait mekanik özellikler firma tarafından ürün ile beraber verilmiştir. Malzemenin blok yoğunluğu 8.8 $\mathrm{gr} / \mathrm{cm}^{3}$ ve elastik modülü $215 \mathrm{GPa}^{\prime} \mathrm{d} \imath \mathrm{r}$.

Hassas döküm kalıplarında numune modeli olarak kullanılmak üzere üç değişik boyutta açık gözeneklere sahip poliüretan köpükleri kullanıldı. Gözenek oranları, bir inç başına düşen gözenek sayısı 
(ppi; porous per inch), sırasıyla 10,20 ve 30 ( \pm ) 3 olarak verilmiştir. Numune modellerinin ölçüleri $12 \mathrm{~mm}$ çapında ve $14 \mathrm{~mm}$ boyunda olacak şekilde hazırlandı. 30 ( \pm 3$)$ ppi gözenek oranına sahip poliüretan köpükten hazırlanan numune modelinin önden ve yandan görünüşü Şekil 1'de verilmiştir.

Tablo 1. Çalışmada kullanılan alaşımın oranları(Böhler) (Table 1. Alloy chemical composition)

\begin{tabular}{|l|c|}
\hline Malzeme Adı & Karışım Oranı (\%) \\
\hline Nikel & Bal. \\
\hline Krom & 26.0 \\
\hline Molibden & 11.0 \\
\hline Silisyum & 1.5 \\
\hline Karbon & $<0.05$ \\
\hline
\end{tabular}

Tablo 2. Alaşımın bazı mekanik özellikleri

(Table 2. Some mechanical properties of alloy)

\begin{tabular}{|l|l|}
\hline Gerilme mukavemeti & $580 \mathrm{MPa}$ \\
\hline Blok Yoğunluk & $8.8 \mathrm{gr} / \mathrm{cm}^{3}$ \\
\hline Vickers sertliği & $195 \mathrm{HV}$ \\
\hline Elastik modülü & $215 \mathrm{GPa}$ \\
\hline Ergime sıcaklığı aralığı & $1280-1350{ }^{\circ} \mathrm{C}$ \\
\hline Döküm sıcaklığı & $1410^{\circ} \mathrm{C}$ \\
\hline
\end{tabular}

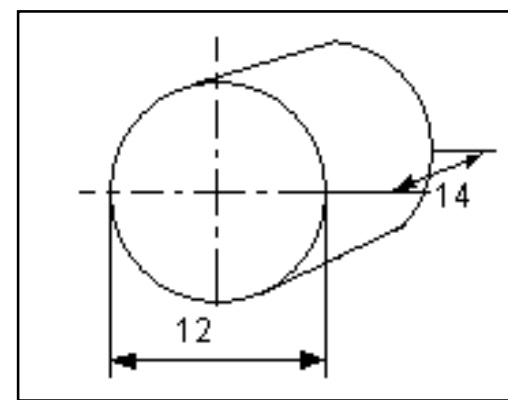

Şekil 1. Numune modeli taslak ölçüleri ve modelin önden ve üstten görünüşü $(\varnothing 12 \times 14 \mathrm{~mm})$

(Figure 1. Draft measure of samples and front and top views ( $\varnothing 12 \times 14$ $\mathrm{mm})$ )

Hazırlanan numune modelleri hassas dökümde kullanılan mum yolluklar vasıtasıyla her bir döküm ağacında dört numune olacak şekilde eritilerek model ağacına yapıştırılmıştır. Daha sonra silindirik bir plastik gömlek model ağacın etrafına geçirilerek alçı karışım silindirik gömlek ile model ağaç arasında kalan tüm boşluklarına ulaşması için doldurma işlemi titreşimli bir zemin üzerinde gerçekleştirilmiştir. Hazırlanan kalıp bloklar döküm hazırlığı için termokupol fırında $1000^{\circ} \mathrm{C}^{\prime}$ de 1 saat süre ile ısıtılmak suretiyle kalıp içerisindeki model ve yollukların yanarak uçması sağlanarak kalıp içerisinde döküm boşluğu oluşturulmuştur. Kalıpların soğumasına fırsat vermeden, hızlı bir şekilde pota içindeki Ni-Cr-Mo alaşım $1410^{\circ} \mathrm{C}^{\prime}$ de ergitilerek savurmalı döküm cihazında dökülmüştür. Döküm alçısı artıkları, alçı temizleme makinesinde kum fırtınasına maruz bırakılarak temizlendi. Daha sonra numune etrafındaki kalıp yollukları kesilerek, numune kullanıma hazır hale getirilmiştir (Şekil 2) . 


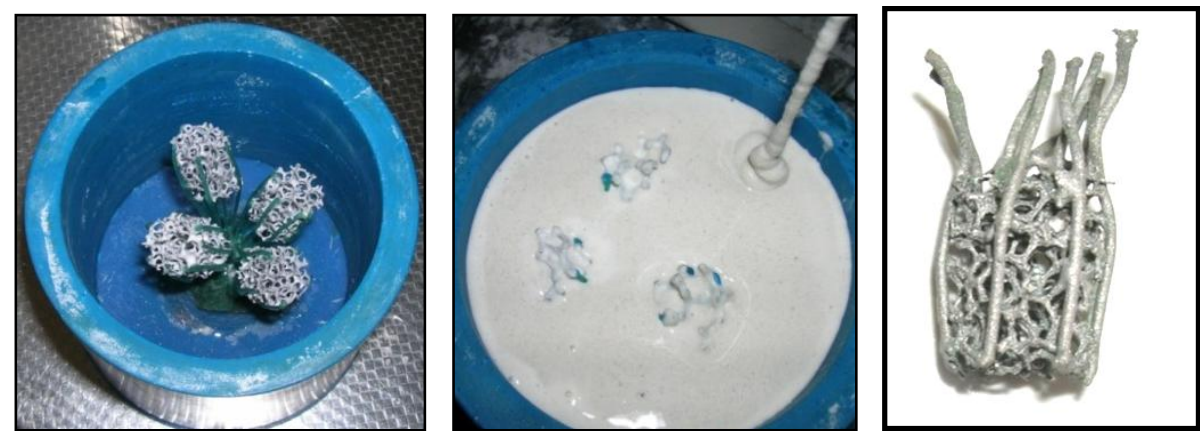

Şekil 2. Döküm ağacının oluşumu, alçı kalıbın hazırlanması ve üretilmiş numune

(Figure 2. Cast tree formation, Preparation of plaster mold, Produced sample)

\subsection{Yoğunluk Ölçümü (Gözeneklik Oranının Belirlenmesi)}

Gözenek boyutları birbirinden farklı olan numunelerin, döküm işlemi sonunda sahip oldukları yoğunluklarını hesaplamada kütle ve hacim ilişkisi kullanıldı. Dolu haldeki tam metal yoğunlukları ( $\left.\rho_{\text {Tam }}\right)$ ve gözenekli metal numunelerin yoğunluklarını ( $\rho_{\text {Gözenek) tespit etmek }}$ için 3.1. no'lu formül kullanıldı. Daha sonra her bir numunenin elde edilen bu yoğunluk değerleri kullanılarak, \% gözeneklik miktarları ( $\boldsymbol{\varepsilon}$ ) 3.2. no'lu formül ile belirlendi [7].

$\rho_{\text {Gözenek }}=\frac{m}{v}$

$m:$ Kütle, gr

$\mathrm{v}$ : Hacim, $\mathrm{mm}^{3}$

$\varepsilon=\left(1-\frac{\rho_{\text {Gözenek }}}{\rho_{\text {Tam }}}\right) x 100$

$\boldsymbol{\varepsilon} \quad$ : Gözeneklik miktarı (을

$\rho_{\text {Gözenek }}$ Görünür Yoğunluk $\left(\mathrm{gr} / \mathrm{mm}^{3}\right)$

$\rho_{\text {Tam }}$ : Tam Yoğunluk $\left(\mathrm{gr} / \mathrm{mm}^{3}\right)$

\section{DENEY SONUÇLARI (FINDINGS)}

Bu çalışmada, üç değişik gözenek boyutunda ve (ø12x14 mm) ebatlarında üretilen numunelerin yoğunlukları hesaplandı ve ortalama değerler bulundu (Tablo 3). Gözenek boyutları, bir inç' teki gözenek sayısına (ppi; porous per inch) göre belirlendi. Döküm işlemi sonunda numunelerin sahip oldukları yoğunluklarını hesaplamak için kütle ve hacim ilişkisi kullanıldı. Numunelerde kapalı gözenek olmadığından hacim, sıvı tartı (liquid weighing) yöntemi ile belirlendi [7]. Alaşımın dolu haldeki tam yoğunluğunu ( $\left.\rho_{\text {Tam }}\right)$ ve gözenekli numunelerin yoğunluklarını ( $\rho_{\text {Gözenek }}$ ) tespit etmek için 3.1. no'lu formül kullanıldı. Daha sonra her bir numunenin elde edilen bu yoğunluk değerleri kullanılarak, yüzde gözeneklik miktarları ( $\boldsymbol{\varepsilon}$ ) 3.2 . no'lu formül ile belirlendi [7 ve 8]. Dökümde kullanılan alaşımın tam yoğunluğu ve numunelerin gözenek boyutu (ppi), gözenekli yoğunlukları 
ile beraber ortalama gözeneklik miktarları da tespit edilerek Tablo 4'de verilmiştir.

Tablo 3. Gruplara göre numunelerin yoğunluk ölçümleri

(Table 3. Average porosities of the specimens by groups)

\begin{tabular}{|c|c|c|c|c|}
\hline & $\begin{array}{l}\text { 1. Numune } \\
\text { Gözeneklik }\end{array}$ & $\begin{array}{l}\text { 2. Numune } \\
\text { Gözeneklik }\end{array}$ & $\begin{array}{l}\text { 3. Numune } \\
\text { Gözeneklik }\end{array}$ & $\begin{array}{c}\text { Ortalama } \\
\text { Gözeneklik }\end{array}$ \\
\hline & miktarı (ㅇ) & miktarı (ㅇ) & miktarı (잉 & miktarı (ㅇ) \\
\hline A grubu & 89,6 & 91 & 91,5 & 90,7 \\
\hline B Grubu & 78,9 & 80,3 & 83,8 & 81,0 \\
\hline C Grubu & 66,8 & 68,1 & 72,8 & 68,8 \\
\hline
\end{tabular}

Tablo 4. Gözenek oranına göre ortalama gözenek oranları (Table 4. General porosities by the pore sizes)

\begin{tabular}{|c|c|c|c|c|c|}
\hline $\begin{array}{c}\text { Numune } \\
\text { Grubu }\end{array}$ & $\begin{array}{c}\text { Alaşım } \\
\text { İ̧̧eriği }\end{array}$ & $\begin{array}{c}\text { Tam } \\
\text { Yoğunluk } \\
\left(\mathrm{gr} / \mathrm{mm}^{3}\right) \\
\left(\rho_{\text {Tam }}\right)\end{array}$ & $\begin{array}{c}\text { Gözenek } \\
\text { Oranı } \\
(\mathrm{ppi})\end{array}$ & $\begin{array}{c}\text { Nispi } \\
\text { Yoğunluk } \\
\left(g r / \mathrm{mm}^{3}\right) \\
\rho_{g}\end{array}$ & $\begin{array}{c}\text { Gözeneklilik } \\
\text { Miktarı (\%) }\end{array}$ \\
\hline A & Ni-Cr-Mo & 0,0088 & $10 \pm 3$ & 0,0008 & 90,7 \\
\hline B & Ni-Cr-Mo & 0,0088 & $20 \pm 3$ & 0,0017 & 81,0 \\
\hline C & Ni-Cr-Mo & 0,0088 & $30 \pm 3$ & 0,0027 & 68,8 \\
\hline
\end{tabular}

Tablo 4'deki yüzde gözeneklik miktarı, nispi yoğunluk ve gözenek oranlarının verileri beraber değerlendirildiğinde; en büyük gözenek boyutuna sahip A grubu numunelerin, ortalama gözeneklik miktarının da en büyük değerde olduğu görülmektedir. A grubu numunelerde bir inçteki gözenek sayısı 10 ( \pm 3$)$ dur. Ayrıca numunelerdeki telcik kesitlerinin artıp azalması, numunelerin gözenekli yoğunluğunun artıp azalması ile doğru orantılıdır. 1 inç'teki gözenek sayısı 20 ( \pm 3$)$ olan B grubu numune verilerini incelediğimizde, ortalama gözeneklik miktarının A grubu numunelere göre azaldığı görülmektedir. Bu sonuç aynı ebatlara sahip olan numunelerin gözenekli yoğunluğunun, gözenek oranlarıyla doğru orantılı olarak düştüğünü göstermektedir. Burada her üç numune grubunun ortalama gözeneklik miktarının, gözenek boyutları paralel olarak düzenli değişmemesi, numunelerde ki telcik kesitlerinin aynı olmaması ile ilgilidir.

\section{TARTIŞMA VE SONUÇ (DISCUSSSION AND CONCLUSION)}

$\mathrm{Bu}$ çalışmada; $\mathrm{Ni}$ esaslı Ni-Cr-Mo alaşım hassas döküm yöntemiyle, açık gözenekli bir yapıda ve değişik gözenek boyutları ve telcik kalınlıklarında üretilmiştir. Üretilen numunelerin yoğunlukları ve gözenek boyutları ölçülerek şu sonuçlara ulaşılmıştır.

Kullanılan malzemenin üretim yöntemine ilişkin olarak Curran, (2001); Metal tozlarıyla, toz metalurjisi yöntemi ile elde edilen köpüklerin mukavemetinin metal veya fiber tanecikleri arasında ki en küçük temas noktalarıyla ilgili olduğunu ifade etmiştir. Bu tür toz metalurjisi yöntemi ile elde edilen köpüklerin üretim yöntemlerine göre, kendine özgü mukavemetlerinin düşük olduğunu belirtmiştir. Yamada ve arkadaşları, (2000) ise; Poliüretan köpük ön modelli, infilitrasyon yöntemi ile açık gözenekli yapıda döküm gerçekleştirmiş ve üretilen malzemelerin yüksek kaliteli ve güvenilir olduğunu, gözeneklik oranının o98 oranına kadar çıkabileceğini ifade etmiştir. Yamada bu yöntemle herhangi bir alaşım veya metalin dökülebileceğini de belirtmiştir. Yamada, (2000) Al ve Mg malzemelerini kullanarak, poliüretan köpük model ve infilitrasyon yöntemi ile elde ettiği numunelerde Al için; $0.0471 \mathrm{gr} / \mathrm{mm}^{3}$ ile $0.0653 \mathrm{gr} / \mathrm{mm}^{3}$ aralığında $\mathrm{Mg}$ için; $0.028 \mathrm{gr} / \mathrm{mm}^{3}$ ile $0.030 \mathrm{gr} / \mathrm{mm}^{3}$ aralığında nispi yoğunlukta 
değerler elde etmiştir. Bu çalışmada ise; Yamada'nın (2000) yaptığı çalışmadan farklı olarak infilitrasyon döküm yerine savurmalı döküm cihazı kullanılmıştır. Savurmalı döküm cihazında da, hassas döküm yöntemi ile üretilen numunelerin gözenek boyutları ve telcik kesitlerinin kontrol edilebilirliği gösterilmiştir. Poliüretan köpük model kullanımına bağlı olarak üniform yapıda gözenekler elde edilmiştir. Tüm gözenekler model olarak kullanılan poliüretan köpük gözenekleriyle benzerdir. Özgül ağırlığı daha yoğun bir metal olan NiCr-Mo $\left(0.0088 \mathrm{gr} / \mathrm{mm}^{3}\right)$ alaşımı için; $0.0008 \mathrm{gr} / \mathrm{mm}^{3}$ ile $0.0027 \mathrm{gr} / \mathrm{mm}^{3}$ aralığında nispi yoğunluk değerleri elde edilmiştir.

Gözenekli kemik yerine implante edilecek gözenekli malzemenin ortalama gözenek boyutunun kemik ilerlemesine imkan verecek ölçülerde olması gerekmektedir. Clemow (1981) bu değerin yaklaşık olarak 200-500 um civarında olması gerektiğini belirtmiştir. Bu çalışmada 85-127 ve 254 m değerleri kullanılmıştır[6]. Yumuşak ve sert dokunun gelişip implantın gözeneklerini doldurması, kemiğin implanta fikse olması açısından, implant gözenek boyutlarının uygun olduğunu göstermiştir.

- Ni-Cr-Mo alaşımı olan bir malzemenin savurmalı döküm cihazında, hassas döküm yöntemi ile açık gözenekli yapıda ve ㅇ66,8 ile ○91,5 yoğunluk aralığında, ikinci bir işleme gerek kalmadan nihai şekli ile başarılı bir şekilde üretilebileceği görülmüştür.

- Poliüretan köpük model kullanımına bağlı olarak üniform yapıda gözenekler elde edilmiştir. Tüm gözenekler model olarak kullanılan poliüretan köpük gözenekleriyle benzerdir.

- Savurmalı döküm cihazında, hassas döküm yöntemi ile üretilen numunelerin gözenek boyutları ve telcik kesitlerinin kontrol edilebilirliği gösterilmiştir.

- Numunelerin yoğunluk değerleri incelendiğinde, nispi yoğunluğun artan gözenek boyutu ve telcik kesiti ile ilgili olduğu görülmüştür.

\section{KAYNAKLAR (REFERENCES)}

1. Wadley, H.N.G., (2001). Cellular Metals and Metal Foaming Technology, Verlag MIT.

2. Gibson, L.J. and Ashby, M.F., (1997). Cellular Solids: Structure and Properties, Cambridge University Press.

3. Curran, D., (2001). Metal Foams, Cambridge University Press.,

4. Yamada, Y., Shimojima, K., Sakaguchi, Y., Mabuchi, M., Nakamura, M., Asahina, T., Mukai, T., Kanahashi, H., and Higashi,K., (2000). Effects of Heat Treatment on Compressive Properties of AZ91 Mg and SG91A Al Foams with Open-Cell structure, Material Science and Engineering, A280, 225-228.

5. Wen, C.E., Mabuchi, M., Yamada, Y., Shimojima, K., Chino, Y., and Asahina, T., (2001). Processing of Biocompatible Porous Ti and Mg., Scripta Materialia, 45, 1147-1153.

6. Clemow, J.T., Weinstein, A.M., Klawitter, J.J., Koeneman, J., and Anderson, J., (1981). J. Biomed Material Research, Volume 15,73 .

7. Li, B.Y., Rong, L.J., Li, Y.Y., and Gjunter, V.E., (2000). Synthesis of porous Ni-Ti Shape Memory by Self-Propagating High-Temperature Synthesis: Reaction Mechanism and Anisotropy in Pore Structure, Acta Materialia, 48. pp:3895-3904.

8. Demirer, A., (2011). The Exemination of Weld Line Properties in Injection Molded pp and pp Composites, e-Journal of New World Sciences Academy, 6 (4), pp:1556-1564. 